\title{
Criticizing School-related Gender-based Violence: A Cultural Analysis on the Music Video Womxnly
}

\author{
Jing Zhou \\ Applied Foreign Language Department, Guangdong Business and Technology University, Zhaoqing, China \\ Email address: \\ 1227118655@qq.com

\section{To cite this article:} \\ Jing Zhou. Criticizing School-related Gender-based Violence: A Cultural Analysis on the Music Video Womxnly. International Journal of \\ Literature and Arts. Special Issue: Humanity and Science: China's Intercultural Communication with the Outside World in the New Era. \\ Vol. 8, No. 3, 2020, pp. 142-147. doi: 10.11648/j.ijla.20200803.16
}

Received: February 27, 2020; Accepted: March 18, 2020; Published: April 14, 2020

\begin{abstract}
Gender-based violence, a deeply-rooted violence directed against a person because of their gender, remains one of the most notable human rights violations in all societies. Both women and men experience gender-based violence. It is school-related in many cases and often occurs in and around schools, so it is sometimes referred to as "school-related gender-based violence" (shortened as SRGBV). As one of the manifestations of gender-based violence, SRGBV is complex and multifaceted and attracts great attention from the international community. Applying such cultural theories as carnival theory, the other image, gender performativity, the functions of arts and popular culture, the present essay concentrates on the practitioners of diverse gender temperament like "sissy", "tomboy" or "gender fluid" in SRGBV and analyzes how the composers of the music video Womxnly achieve their goal to draw the public attention to the MV and to arouse social respect of gender diversity in schools. The essay is divided into four sections with the first giving the social background and purpose of the $\mathrm{MV}$, the second introducing the cultural theories used in the production of the MV, the third analyzing the MV in details respectively from the perspective of music, video and cultural studies, and the last concluding the research in this paper.
\end{abstract}

Keywords: School-related Gender-based Violence, Cultural Analysis, Womxnly, Diverse Gender Temperament

\section{Introduction}

School-related gender-based violence (shortened as SRGBV) defined as "any act or threat of sexual, physical or psychological violence occurring in and around schools, perpetrated as a result of gender norms and stereotypes, and enforced by unequal power dynamics" [1] and violating children's fundamental rights is a form of gender discrimination, and has wide-ranging consequences for children's physical and emotional well-being, school performance and attendance, and likelihood of experiencing or perpetrating future violence. School Gender-based violence is emphasized as doing physical, sexual, psychological or economic harm, including threats of such acts, coercion or arbitrary deprivation of liberty, whether occurring in public or in private life. (See Figure 1) [1] According to UNESCO's Global Guidance Addressing School-related Gender-based Violence in 2016, 246 million children are subject to some form of gender-based violence in and around school worldwide every year, [1] which shows that school is not a safe place that it should be.

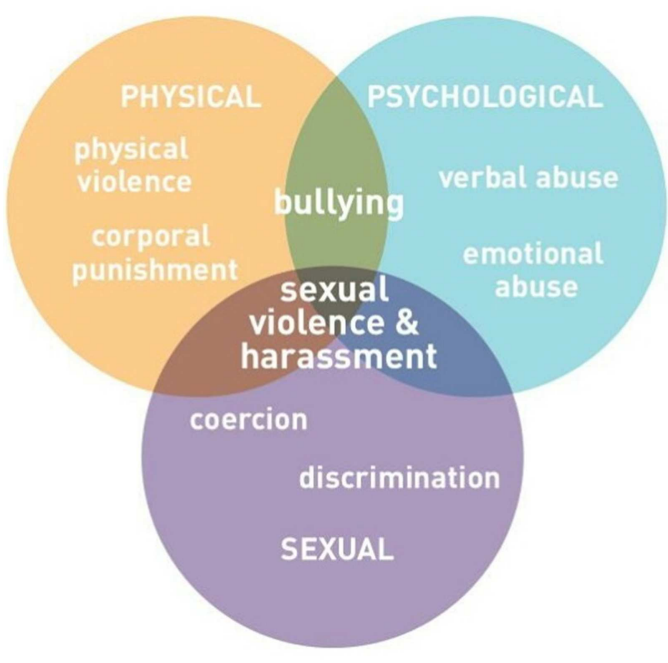

Figure 1. Different forms of SRGBV. 
In a world of binary opposition which is a key concept in structuralism that states that all elements of human culture can only be understood in relation to one another and how they function within a larger system or the overall environment, [2] it is generally believed that masculinity is opposed to femininity and that male should be masculine while female should be feminine. Ban Zhao, living in the Eastern Han Dynasty of China, tells us in his Women's Commandments, "As Yin and Yang are not of the same nature, man and woman have different characteristics. The distinctive quality of the Yang is rigidity; the function of the Yin is yielding. Man is honored for strength, while a woman is regarded as beautiful on account of her gentleness." This view is still held by many people today. [3] Today's adolescents are living in a world quite different from that of the previous generations, but the society still views them too often for what they should be like instead of who they are. Those who develop the hobbies of different sex in school are usually taken as abnormal or freak and the discrimination against "sissy" (a man whose language and acting are with more feminine traits), "tomboy" (a woman whose language and acting are with more masculine traits) [4] or "gender fluid" (a gender identity which refers to a gender which varies over time) [5] often make them the victims of school violence. It is worth noting that for a long time we have been thinking about gender violence in terms of the binary gender division between men and women, ignoring the existence of other genders, which is itself a kind of violence. The group of sissy, tomboy or gender fluid is becoming bigger and bigger in the world. So is it in China, just as Guan Wenyu mentions in her master dissertation "... because of Chinese reform and opening-up policy, western countries' thinking patterns have had an unprecedented impact on the Chinese. Such as an increase in homosexuals, transsexuals, and among other gender identities. Those reasons have also caused an increase in tomboys and sissies." [4]

14-year-old Yeh Yung-Chih fom Taiwan, always mocked as a sissy by some schoolmates, was found lying in a pool of blood in school toilet in the year 2000, and he died after being taken to the hospital. With Yeh's mother's persistent fight against the official response to the circumstance, Taiwan passed Gender Equity Education Act in 2002-- two years after Yeh Yung-Chih's passing. Getting inspiration from the story, Cai Yilin and her partners composed the song Womxnly, "Song of the Year" of the 30th Taiwan Golden Melody Festival, which was then in 2019 developed into a MV. Taking Yeh Yung-Chih as the archetype, the song Womxnly is devoted to the adolescents who are bullied in school. On February 15 of the year 2019, Cai Yilin posted the music video Womxnly on her blog with the caption, "When dancing is no longer for comparison or competition, it is just an expression, an outlet and a lifestyle--just because you are shaking your body so boldly, spontaneously and freely without caring about how others will think of it. How would you like to express yourself? Thank you, all the extraordinary boys and girls like Yeh Yung-Chih. I believe our stories will continue to be rebuilt, rewritten, and admired..." (See Figure 2) To the composers of the song, this song will give much courage to the adolescents with gender temperament different from the traditional gender stereotypes, and be like a ray of sunshine into the abyss where they receive discrimination.

In light of the social construction theory, most of the differences between men and women are not innate, but are learned and imitated in the process of socialization, especially by the construction and shaping of traditional gender norms. From the perspective of differential psychology, the difference between boys and girls is much smaller than that between boys and boys or that between girls and girls. Therefore, it is not enough to pay attention only to the differences in physical sex, and it is necessary to include such contents as roles, characteristics, concepts in social gender development of adolescents. [6] Yeh Yung-Chih is likened to a beautiful rose in the song (just as the title of the original version says in Chinese: Mei Gui Shao Nian). As the lyrics reflects (...You are not guilty. It's the world that is guilty. Being alive is not a $\sin$. You don't need to be sorry... The most beautiful roses have the sharpest thorns, a life in rose hues shall be the cold dish of revenge we serve the haters. Never let anyone change who you are. Boy or girl, you can be whichever you want. There will always be someone willing to cherish you.), the composers of the MV think the practitioners with diverse gender temperament are innocent and should be respected. So they are trying to encourage the adolescents to "Respect the intuitive response of the body" and "Be yourself.", and call people to draw attention to those like Yeh Yung-Chih through it.

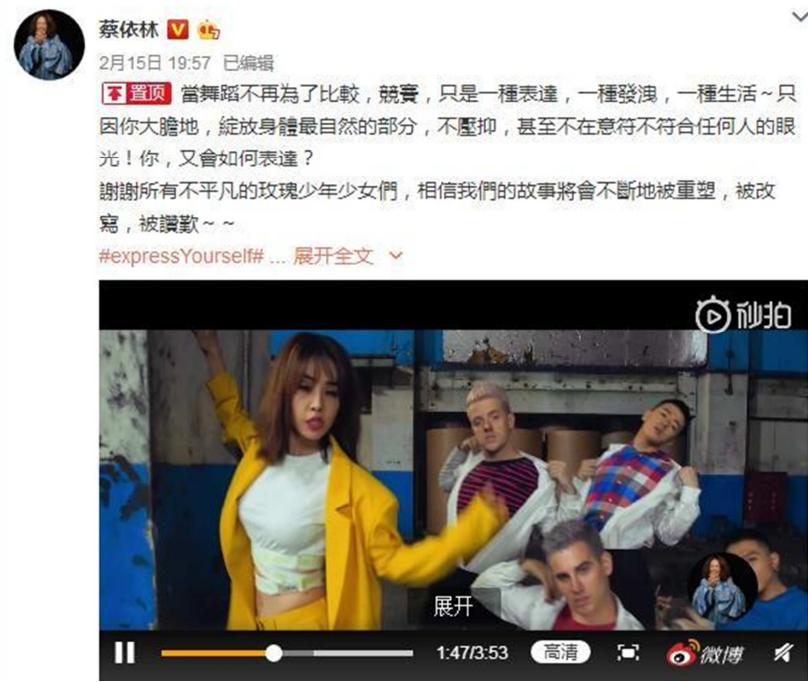

Figure 2. Cai Yilin's blog to declare the publication of MV Womxnly.

\section{Cultural Studies Used in Music Video Womxnly}

\subsection{Carnival Theory}

Carnival theory is proposed by Mikhail Mikhailovich Bakhtin (1895-1975), a distinguished Russian ideologist in the last century, and carries a dramatic weight among his achievements. Carnival theory is based on his study of works 
of Rabelais and Dostoevsky, and embodied in Problems of Dostoevsky's Poetics and Rabelais and His World. Rebellion and renewal are Carnival's spirit. "Carnival celebrates temporary liberation from the prevailing truth from the established order: it marked the suspension of all hierarchical rank, privileges, norms and prohibitions." [7] And it constructs a "second world and a second life outside officialdom". [7] When explaining popular cultural with carnival theory, we can find they are theoriticaly suited, both of them have a critical spirit on reality.

\subsection{The Other Image}

The "self" and "other" is a significant topic in post-colonialism, and they are opposite to each Other. In Orientalism Said says "European culture gained in strength and identity by setting itself off against the Orient as a sort of surrogate and even underground self'. [8] He further indicates Western writings just describe the Orient as a weak, irrational, feminized the "other", but delineate the West being rational, strong, and masculine. It can be known that the "Other" in Orientalism is based on western knowledge structures about the East that lies in a subordinate position in the Binary Opposition and is echoed on the western way of thinking and values, presuming the role of the weak under the western system of powerful discourse. [8] Yu Huang points out that "The Other is opposite to the Self, which means that people and things outside of the Self in the fields of western philosophy, psychology, literature, cultural research and so forth have an interpretation of the Other. The other in western culture signifies marginal, subordinate, inferior, oppressed and excluded" [9]. Nowadays, the other is not just so-called "Eurocentric arrogance of conscience", the concept of the "other" has been extended to the research on sex culture. And "otherization" occupies an important place in cutting-edge sex culture studies. Those who subvert the traditional gender stereotype and possess gender temperament different from what they are thought to have according to the Binary Opposition are often otherized and then become the victims of school violence due to their breaking of the social "norm" [10], like the prototype of the MV.

\subsection{Gender Performativity}

Butler Judith, Maxine Elliot Professor of Comparative Literature at University of California Berkeley, differentiates "gender" from "sex". The former lays stress on social meaning, while the latter physical, which is the basis of "gender performativity". "Early in her books, Butler invites the theory of performances to discuss how gender is constructed through the performances of the body. To her, the body is not only materiality, but also is the continuous materiality of identity. A man has a body, but more important, he "does" his own body. Depending on the repeated performances, the body becomes a historical existence. The physical actions give individual's identity which contains gender, race, and others." [11] Butler puts forward the theory "gender performativity" in her book Gender Trouble that arouses great academic concerns.
According to the theory, the performance of gender is controlled by the pressure of certain norms and disciplines, and the behavior of gender must follow the norms and disciplines (male masculine, female feminine). Or it will be considered as freaky and additionally get discriminated and hurt. "... performative acts must be reproduced to become efficacious." [12], so the performance of gender is not voluntary but compelled. However, "appearance 'outside' the body" is really "essence 'inside' it"? Esther Newton gives answer to the question in her book Mother Camp: Female Impersonators in America:

At its most complex, [drag] is a double inversion that says, "appearance is an illusion." Drag says "my 'outside' appearance is feminine, but my essence 'inside' the body is masculine." At the same time it symbolizes the opposite inversion; "my appearance 'outside' my body, my gender is masculine but my essence 'inside' myself is feminine. [13]

\subsection{Other Related Studies}

The theories on the functions of arts and on popular culture contribute much to the making of the MV. According to Plato, arts should be the integration of the true, the good and the beautiful, and should bring not only pleasure but also the ways to run the state. Namely, the functions of arts should be both entertaining and teaching. [14].

John Fiske mentions in his book Understanding Popular Culture "Popular text must offer popular meaning and pleasures----popular meanings are constructed out of the relevances between the text and everyday life, popular pleasures derive from the production of these meanings by the people, from the power to produce them." [15] As for the role of pleasure in culture, John Fiske thinks it can be divided into two broad categories: the applauded, and the deplored. "Sometimes the antithesis is seen as aesthetic (high, sublime pleasure versus low enjoyment), sometimes political (reactionary versus revolutionary pleasures), sometime discursive (the pleasures of making meanings versus accepting ready-made ones), sometimes psychological (the pleasures of the spirit versus those of the body), sometimes disciplinary (the pleasures of exerting power versus those evading it).’[15]

\section{An Detailed Analysis of Music Video Womxnly}

\subsection{Detailed Analysis of the MV from the Perspective of Music}

The composers are trying to call people to "respect the intuitive response of the body" and "be yourself" through the $\mathrm{MV}$, so they mesh tropical house and dancehall well.

\subsubsection{Tropical House}

Beginning as a joke by Australian producer Thomas Jack but gaining popularity among listeners, tropical house, also known as "trop house", possesses typical house music characteristics, whereas tropical house can be described as 
having a more uplifting and relaxing sound. Tropical house, integrating the timbre of flute, marimba, steel drum, brass instrument and human voice, creates an overall lazy, happy and holiday-like leisure atmosphere for the audience. The overall rhythm of tropical house is relatively slow, which is a relaxing electronic dance style. The style of tropical house suits the themes of the MV, both of which express the desire for freedom and natural instincts.

\subsubsection{Dancehall}

Dancehall is named after Jamaican dance halls in which popular Jamaican recordings were played by local sound systems. Themes of dancehall are about dancing, violence and sexuality. Unlike earlier dancehall, the new evolution of dancehall music was characterized by using structures of music commonly heard in mainstream pop music, such as repeated choruses, melodic tunes, and hooks.

The tenderness and strength of the lyrics are expressed to the point through the combination of the two styles, which creates a fervent and romantic atmosphere and sends the audience to dance off the melancholy they might experience when they know about the story behind the song. With the moving of the body, people can feel the beauty and struggle of Yeh and many other boys and girls like him.

\subsection{Detailed Analysis of the MV from the Perspective of Video}

Chen Kaiju hints that cultural works has great effect on the construction of the image of relative persons. [16] The Producers of the MV understand what it is trying to achieve and how it might get there. Besides the music mentioned above, the following four aspects contribute to the heavy success of the MV:

\subsubsection{Location}

The video is made in an abandoned old factory. (see Figure 3) Appropriately, the industrial style favored by the young people in the field of designing differs from the more traditional view of design where all the parts are subjugated to the betterment of the whole and establishes a sense of freedom and strength, which helps highlight the theme of the song----"Respect the intuitive response" and "Be yourself".

\subsubsection{Subtitle}

Except for the names of the song, the composers and the performers, no other subtitles are given in the MV. By this way, each performer and the title of the song are respectively emphasized. Meanwhile, the audience will get absorbed on the relaxing music and the free performance when they are watching the MV, and even move their own bodies freely to the music like the performers, which lays a foundation for the understanding and spreading of the MV and its theme.

\subsubsection{Clothing}

With the music on, the performers move in the screen. The backup dancers are all in black suits, while Cai Yilin wears a tight-fitting coat inside a casual light yellow suit. The clothing represents the disciplines and norms of the world, which you must be subject to and under the control that you cannot show yourself as much as you like. However, halfway through the $\mathrm{MV}$, the right sleeve of the suit of a backup dancer is torn off, and then all the backup dancers take off the outer coat, and in the last part of the MV, they are all in casual clothing, and Cai also changes the tight-fighting for a sweater. The change of the clothing symbolizes the strong desire to escape from the control of the vulgar disciplines and norms.

\subsubsection{Dance}

Music is the soul of dance. The choice of background music determines the style of the dance. The integration of tropical house and dancehall leads to relaxing, tempting, and wild dancing. The performers have been moving their bodies to the music together till the ending part of the MV when they appear on the screen one by one. Each of them dances in his/her own way, in which the concept of "self" and "freedom" is further enhanced.

\subsection{Detailed Analysis of the MV from the Perspective of Cultural Studies}

\subsubsection{From the Perspective of Carnival Theory}

The Musical Video Womxnly conveys its appeal to full advantage through carnival. "Carnival does not know footlights, in the sense that it does not acknowledge any distinction between actors and spectators...Carnival is not a spectacle seen by the people: they live in it, and everyone participates because its very idea embraces all the people" [7], which is what the composers want the MV to do. When the audience watching the MV dance to the music, they can feel the carnival pleasure of enjoying the freedom of body.

On CCTV's programme--24 Hours on Dec. 5, 2019, a super public square dancing group of several--thousand persons drew people's attention, most of whom were not the seniors but young people. They danced to the music, and moved their bodies at their pleasure without worrying their dance was at random. In fact, any person living in the world full of disciplines and pressures is eager for a carnival moment of the body or mind to some extent. That's also why the MV is widely welcomed.

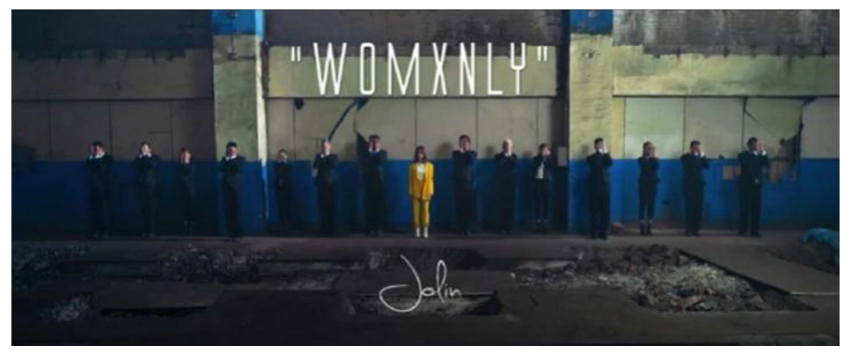

Figure 3. The title scene of the $M V$.

\subsubsection{From the Perspective of the Other Image}

"Otherization" and "marginalization" play an important role in the research of contemporary frontier gender culture. In addition to women who are usually considered to belong to the disadvantaged groups, some practitioners of diverse gender temperament that are different from the mainstream binary 
division and subvert the social gender stereotypes are "otherized" for breaking the "rules" and thus become the targets of violence. In such a violent environment, some people choose to "otherize" themselves and resort to self-destruction or even suicide. In this context, the artistic works like the music video Womxnly is what the society really needs. Out of question, Womxnly emerges at the right time.

When "Womxnly", the title of the song, appears on the screen conspicuously, it attracts the audience's attention. (see Figure 3) We may get not only confused but also interested, since we can't find it in the dictionary. It comes from a feminism movement, meaning that woman is not subordinate to man. But here in the MV the intentional replacing of the letter "a" with " $x$ " like Yeh's cry suggests that the otherized practice should not be taken as "abnormal" and that other gender temperament besides masculinity and femininity should be allowed to exist equally. That is why the word is given special emphasis in the MV.

\subsubsection{From the Perspective of Gender Performativity}

In accordance with Judith Butler's "gender performativity" theory, people in the mainstream society try their best to act as a man or a woman, which also highlights the "perversion" of the practitioners with diverse gender temperament. The prototype of the MV is not a practitioner of "gender performativity", he chooses to follow his heart. But it is sad that he dies young from discrimination and violence. As said in the lyric of the song "Sexuality 当心什么会伤 你”'Sexuality? Cut your throat If your honest), sexuality is the reason why Yeh is bullied to death. The MV calls for social respect of gender diversity on behalf of Yeh and his counterparts. The change of the clothing and dance mentioned above is a good example of the use of "gender performativity."

\subsubsection{From the Perspective of the Function of Arts and Popular Culture}

This part will be devoted to how the theories on the functions of arts and on popular culture influence the production of the MV.

As a popular text of arts, the MV should be useful and able to arouse pleasure. The pleasure from the $\mathrm{MV}$ is multiple - discursive, psychological and disciplinary. It sends message ("Respect the intuitive response of the body" and "Be yourself"), freedom, and strength to the audience in its own way. (See 3.1 Detailed Analysis of the MV from the Perspective of Music and 3.1 Detailed Analysis of the MV from the Perspective of Music). When watching the MV, the audience dance freely to the relaxing music like the performers and feel the meaningful lyrics, from which we know the MV implements successfully the functions of entertaining and teaching as a piece of artistic work.

Chen kaiju says that popular culture is the frontline of the culture development and change, which will lead to the qualitative change of culture after certain accumulation period. [17] The young visitors of the music video Womxnly has been over 500,000 one month since its publication. To some extent, the spreading of the MV is an accumulation of change. After a certain period, we may live in a more harmonious and tolerant world in which nobody will be taken as abnormal or freak for gender temperament.

\section{Conclusion}

Li Yinhe points out that the concept of Yin and Yang first appeared in Chinese culture, and then spread to the west. Many believe that Yin and Yang exist in all cultures, histories and economies. Gender stereotypes become increasingly powerful, rigid and underailable in the process of conforming to themselves, which ultimately establishes a gender order that restricts the freedom of people, impedes the exploration of knowledge while deluding people into thinking that a certain sex should be with corresponding gender temperament, and limits purposive independent behaviors when demanding compliance with gender norms. Nowadays, gender stereotypes are on the wane, and an era of diverse gender temperament is getting closer and closer to us. [3] It's taken as a historical moment when Google provided the user registering with a choice of sex outside male and female. [5]

Now that we are walking towards an era of gender diversity. Discrimination against so-called freaky gender temperament will lead to unimaginably bad consequences. The tragedy of Yeh Yung-Chih reflects the pride and prejudice of the whole society. There seems to be no reason for the early death of Yeh. In this progressively harmonious and diverse society, it is hard to imagine people being bullied for their gender differences, even at the cost of their lives. No matter male or female, a person should have the right to make a choice of how to appear as a true "self". Each person is eager to live as an authenticity. And the society should be more tolerant to those with gender temperament different from the stereotyped, which, I think, is what the makers of the MV get from Yeh's story and why they would like to take the cultural studies mentioned in the essay to highlight the themes of it----"Respect the intuitive response of the body" and "Be yourself", and finally receive heavy success as they expect.

\section{References}

[1] UNESCO. 2016. Global Guidance Addressing School-related Gender-based Violence.

[2] https://study.com/academy/lesson/binary-oppositions-in-literat ure-list-of-examples.html (accessed on Jan. 15, 2020).

[3] Li Yinhe, "The Age of Diverse Gender Temperament". Wen Yuan 2010 (5): 22.

[4] Guan Wenyu. "A Study on the Relationship Between "Tomboy" and "Sissy" and Social Gender Construction", A Dissertation Submitted as a partial fulfillment for the degree of M. A. in Foreign Linguistics \& Applied Linguistics, School of Foreign Languages and Literature, Chongqing Normal University, 2012 .

[5] Ye Pengfei, "Has 'Gender Politics' Been Possessed by the Devil?”, [N], Elite Reference, Mar. 06, 2016 (03). 
[6] Lou Chaohua, "Stereotypes: Gender Development of Children and Adolescents", Exploration and Free Views, 2014 (9): 3132.

[7] Mikhail, Mikhailovich, Bakhtin. Rabelais and His World. Cambridge: Massachusetts Institute of Technology Press., 1968: pp. 10, 6, 7 .

[8] Edward, Wadie, Said. Orientalism. New York: Pantheon. 1978.

[9] Yu Huang. Cultural Self-identity in "the Other": A Study on Chinese Images in Country Driving. 5th International Conference on Arts, Design and Contemporary Education. Moscow, 2019

[10] Fang Gang \& Chen Yaya, Action Toolkit--Ending Gender-based Violence on Campus. Beijing: China Social Sciences Press, 2017.

[11] Li He. The Construction of Gender: Judith Butler and Gender
Performativity. 2nd International Conference on Contemporary Education, Social Sciences and Humanities. [C], 2017.

[12] Butler, Judith. Gender Trouble: Feminism and the Subversion of Identity. New York and London: Routledge. 1990: p. 185.

[13] Esther, Newton. Mother Camp: Female Impersonators in America. Chicago: University of Chicago Press. 1979.

[14] Plato. Plato's Selected Dialogues on Arts. The Commercial Press. 2013: pp. 20-63.

[15] Fiske, John. Understanding Popular Culture. London: Unwin Hyman. 1989: pp. 126, 49.

[16] Chen Kaiju. Otherizing Images of Peasantry in Traditional Chinese Culture. Jianghan Tribune 2007 (8).

[17] Chen Kaiju \& Zhang Jin, "A Critique on Pan-Amusement of Postmodern Culture", [J], Philosophical Research, 2016 (07): 120-126. 